\title{
Usefulness of ultrasonography for the evaluation of cervical lymphadenopathy
}

\author{
Rahul Khanna ${ }^{1 *}$, Avinash Dutt Sharma', Seema Khanna ${ }^{1}$, Mohan Kumar ${ }^{2}$, Ram C Shukla ${ }^{3}$
}

\begin{abstract}
Aim: To evaluate the role of ultrasonography for differentiating cervical lymphadenopathy due to tuberculosis, metastasis and lymphoma.

Methods: Ultrasonography of the neck nodes was carried out prior to FNAC in 192 patients using a $10 \mathrm{mHz}$ linear transducer. The sonographic findings were then correlated with the definitive tissue diagnosis obtained by FNAC or lymph node biopsy.

Results: The most significant distinguishing feature was strong internal echoes seen in $84 \%$ of tubercular lymph nodes. This finding was found in only $11 \%$ of metastatic nodes and absent in lymphomatous nodes. The other findings such as L/S ratio, irregular margins, hypoechoic center, fusion tendency, peripheral halo and absent hilus were helpful in differentiating reactive from diseased nodes but showed considerable overlap in the 3 groups of tubercular, metastatic and lymphoma lymph nodes.

Conclusion: Ultrasonography is noninvasive and can give useful clues in the diagnosis of cervical lymphadenopathy. It should be interpreted in conjunction with FNAC result. Ideally ultra-sonographic guided FNAC should be obtained from the sonographically most representative node. In FNAC indeterminate cases, sonographic features may obviate the need for an invasive lymph node biopsy.
\end{abstract}

\section{Introduction}

Cervical lymph nodes are frequently involved in a number of disease conditions. The most commonly seen causes of cervical lymphadenopathy are tuberculosis, distant metastasis and lymphoma. Fine needle aspiration cytology is used for evaluating enlarged cervical lymph nodes and has a high degree of sensitivity and specificity. However in our experience in almost $20 \%$ of patients FNACs may give an equivocal report, which would not contribute to the treatment. Ultrasonography has often been used to map out and characterize cervical lymph nodes specially for differentiating tubercular from malignant lymph nodes. The present study was designed to evaluate the role of ultrasonography for differentiating cervical lymphadenopathy of various causes.

\footnotetext{
* Correspondence: dr_rahul_khanna@rediffmail.com

'Department of Surgery, Institute of Medical Sciences, Banaras Hindu University, Varanasi - 221005 , India Full list of author information is available at the end of the article
}

\section{Materials and methods}

The study was carried out over a 3 years period from January 2005 to December 2007 in the Department of Surgery, Banaras Hindu University. During this period, 204 patients with clinically palpable and untreated cervical lymph nodes visited our Out Patient Department. Out of these 192 patients were included in the study with tissue diagnosis of reactive lymph node, tubercular, metastatic or lymphoma involving cervical lymph nodes. Twelve patients were excluded as they had miscellaneous tissue diagnosis including bacterial, sarcoid and granulomatous lymphadenitis. There were 104 male and 88 female patients and the mean age was 47 years (range 8-71 years). These patients underwent an ultrasonographic examination of their neck nodes followed by FNAC of the most representative lymph node. The ultrasonographic findings were not available to the pathologist who performed the FNAC. The mean number of lymph nodes examined ultrasonographically per patient was 3.8 (range 1-9). In 34 patients (18\%), the FNAC results were equivocal and a subsequent excisional biopsy of the lymph node was done to confirm
Ciomed Central 
the diagnosis. Correlation of the ultrasonographic findings with tissue diagnosis was done later.

\section{Method of ultrasonography}

Ultrasonography was done using a $10 \mathrm{mHz}$ linear transducer. The subject lay supine on the couch with the shoulders supported by a pillow and the neck hyper extended. Scans were obtained with the transducer placed transversely and longitudinally and measurements made in the plane that showed a maximum cross sectional area. Ultrasonographic characteristics were described as delineation of multiple lymph nodes, a tendency towards fusion, an internal echo, an irregular margin, the presence of strong echoes and posterior enhancement. Multiple lymph nodes were defined as involvement of more than 2 nodes. Fusion of lymph nodes was defined as partial or complete disappearance of a borderline echo between them. The internal echo of lymph nodes was assessed by the presence of hyperechoic echogenicity. Strong echoes were defined as single or multiple coarse high-echo spots located focally either in the central or peripheral area of the node. The shape of the lymph node was assessed by the $\mathrm{L} / \mathrm{S}$ (long axis/short axis) ratio. An $\mathrm{L} / \mathrm{S}$ ratio $<2$ indicates a round node whereas an $\mathrm{L} / \mathrm{S}$ ratio $>2$ indicates an oval or elongated node.

\section{Method of FNAC}

Fine Needle Aspiration Cytology (FNAC) of the most prominent node was carried out using a 22 Gauge needle attached to a $10 \mathrm{ml}$. syringe. Multiple passes using negative suction and through a single puncture site were done. This ensured that both the cortical and subcapsular areas of the node were sampled. Half of the aspirate was spread out onto a slide; air-dried and stained using MGG stain. The remaining half of the smear was wet fixed in alcohol-ether mixture and stained by Papanicolou stain. Two to three samples were obtained per lymph node and Cytotech was not used to check for adequacy of the sample.

The results of $\mathrm{L} / \mathrm{S}$ ratio (long axis to short axis ratio) were expressed as a ratio of the respective sizes. The rest of the parameters were described as percentage positive out of the total number of lymph nodes examined. Statistical analysis and calculation of 'p values' was done by student's $t$ test and Fisher's exact probability test.

\section{Results}

Among the 192 patients a total of 730 lymph nodes were evaluated ultrasonographically. The various parameters studied were L/S ratio (long axis to short axis ratio) of lymph nodes, margins, hypoechoic center, fusion tendency, peripheral halo, absent hilus and strong internal echoes. Following ultrasonography, FNAC of the most prominent node was carried out. In 34 patients (18\%), the FNAC result was equivocal and a subsequent excision biopsy of the lymph node was carried out to confirm the diagnosis. Core needle biopsy was not attempted as it is difficult to do on lymphnodes less than $1.5 \mathrm{~cm}$ in size and there is a risk of injury to underlying vascular structures. The final tissue diagnosis obtained on the basis of FNAC or biopsy was: Tubercular lymphadenopathy: 62(32\%), metastatic deposit: 18 (9\%), lymphoma: 14(7\%) and reactive lymph node: 98 (51\%). (Table 1).

On ultrasonography, the long axis to short axis ratio of reactive lymph nodes was highest at 2.2 followed by 1.8 in tubercular, 1.5 in lymphoma and least in metastatic lymph nodes at $1.2(\mathrm{p}<0.01)$. Fusion tendency, peripheral halo and internal echoes were not found in any of the reactive lymph nodes. Fusion tendency was found in $81 \%$ of tubercular, $66 \%$ of metastatic and $14 \%$ of lymphomatous nodes ( $p>0.01$ ). Significant differentiating feature among the 3 types of nodes were the presence of a peripheral halo and internal echoes. Peripheral halo was found in $84 \%$ of tubercular, $55 \%$ of metastatic and $7 \%$ of lymphoma nodes $(\mathrm{p}<0.01)$. Internal echoes were reported in $84 \%$ of tubercular, $11 \%$ of metastatic and none of lymphoma nodes $(\mathrm{p}<0.001)$.

Other ultrasonographic features such as an irregular margin, hypoechoic center and absent hilus were significant only as far as differentiating pathological from

Table 1 Ultrasonographic findings correlated with tissue diagnosis in cervical lymph nodes of 192 patients

\begin{tabular}{|c|c|c|c|c|c|}
\hline Characteristics & $\begin{array}{l}\text { Tubercular } \\
(\mathrm{n}=62)\end{array}$ & $\begin{array}{c}\text { Metastatic } \\
(\mathrm{n}=18)\end{array}$ & $\begin{array}{l}\text { Lymphoma } \\
\qquad(\mathrm{n}=14)\end{array}$ & $\begin{array}{l}\text { Reactive } \\
(n=98)\end{array}$ & $p$ value \\
\hline L/S Ratio & $1.8 \pm 0.6$ & $1.2 \pm 0.3$ & $1.5 \pm 0.4$ & $2.2 \pm 0.9$ & $<0.01$ \\
\hline Irregular margins & $41(66 \%)$ & $10(55 \%)$ & $3(21 \%)$ & $7(7 \%)$ & $>0.01$ \\
\hline Hypoechoic center & $48(77 \%)$ & $11(61 \%)$ & $3(21 \%)$ & $8(8 \%)$ & $>0.01$ \\
\hline Fusion tendency & $50(81 \%)$ & $12(66 \%)$ & $2(14 \%)$ & $\mathrm{Nil}$ & $>0.01$ \\
\hline Peripheral halo & $52(84 \%)$ & $10(55 \%)$ & $1(7 \%)$ & $\mathrm{Nil}$ & $<0.01$ \\
\hline Internal echoe & $52(84 \%)$ & $2(11 \%)$ & $\mathrm{Nil}$ & $\mathrm{Nil}$ & $<0.001$ \\
\hline Absent hilus & $16(26 \%)$ & $15(83 \%)$ & $4(28 \%)$ & $9(9 \%)$ & $<0.01$ \\
\hline
\end{tabular}

The ' $p$ values' compare the significance of difference between metastatic and lymphomatous nodes considered together versus the tubercular lymph nodes. 
reactive lymph nodes were concerned. Among reactive nodes, irregular margins were found in $7 \%$, hypoechoic center in $8 \%$ and absent hilus in $9 \%$ of nodes. The presence of irregular margins among tubercular nodes was $66 \%$, metastatic nodes $55 \%$ and lymphoma nodes $21 \%$ ( $p>0.01$ ). Hypoechoic center was reported in $77 \%$ of tubercular, $61 \%$ of metastatic and $21 \%$ of lymphoma nodes ( $p>0.01$ ). Nodal hilus was absent in $26 \%$ of tubercular, $83 \%$ of metastatic and $28 \%$ of lymphoma nodes $(\mathrm{p}>0.01)$.

\section{Discussion}

Differentiation between tubercular, metastatic and lymphomatous cervical lymph nodes is extremely important from the therapeutic viewpoint. It is also important to make the correct diagnosis at the earliest because a delayed diagnosis can lead to upstaging of the malignancy making a curable lesion incurable. Clinicians have traditionally relied on FNAC to achieve a tissue diagnosis in cervical lymphadenopathy. The reported sensitivity and specificity of FNAC in the evaluation of cervical lymph nodes are $82 \%$ and $97 \%$ respectively [1]. However the FNAC report is frequently equivocal. Tubercular lymph nodes may be labeled as reactive or granulomatous lymphadenitis, which puts the treating doctor in a dilemma regarding starting anti tubercular treatment. Similarly in metastatic lymph nodes, sampling errors might occur because the lymph node chosen for FNAC may be reactive while the secondary deposit is harbored by other lymph nodes. Also FNAC is unreliable in differentiating between a metastatic and lymphomatous lymph node. Core needle biopsy is difficult to obtain from cervical lymph nodes. This is because of their small size, typically less than $1.5 \mathrm{~cm}$. Trying to obtain a core needle biopsy especially with a tru cut needle from such small nodes puts the underlying vascular structures at risk of injury. The present study demonstrates the usefulness of ultrasonography used as an adjunct to FNAC in diagnosis of cervical lymphadenopathy.

The important ultrasonographic features of lymph nodes diagnosed on FNAC or histology to be reactive were a high $\mathrm{L} / \mathrm{S}$ ratio (2.2) and absence of fusion tendency, peripheral halo and internal echoes. Irregular margins were found in only $7 \%$, hypoechoic center in $8 \%$ and absence of hilus in $9 \%$ of reactive lymph nodes.

The ultrasonographic characteristics of tubercular lymphnode are said to be multiple lymph nodes, fusion tendency of adjacent nodes and a hypoechoic center with posterior enhancement. An additional feature, which has great specificity for tubercular lymphadenitis is strong echoes within the mass. The strong echoes are calcification within the node $[2,3]$. We found strong internal echoes in $84 \%(52 / 62)$ of tubercular lymphnodes and $11 \%(2 / 18)$ of metastatic lymph nodes. Internal echoes were absent in lymphomatous nodes.

Metastatic nodes are ultrasonographically characterized by a smaller long axis to short axis ratio ( $\mathrm{L} / \mathrm{S}$ ratio), absence of hilus and a hypoechoic center. We found that the mean $\mathrm{L} / \mathrm{S}$ ratio of metastatic nodes was $1.2 \pm$ 0.3 , of lymphomatous nodes $1.5 \pm 0.4$ and tubercular lymph nodes $1.8 \pm 0.6$. An absent hilus was found in $83 \%(15 / 18)$ of metastatic nodes while only $26 \%(16 / 62)$ of tubercular and $28 \%(4 / 14)$ of lymphomatous nodes had absent hilus. This was because metastatic nodes tend to assume a more spherical shape. Steinkamp HJ et al report that $95 \%$ of metastatic nodes had L/S ratio of less than 2 [4]. We also found a hypoechoic center in $61 \%(11 / 18)$ of metastatic lymph nodes which could reflect central necrosis. Fusion tendency was found in $66 \%(12 / 18)$ of metastatic nodes which could denote extra nodal spread and should be considered as a prognostic sign and also the need for post surgery adjuvant radiotherapy. Kim $\mathrm{HC}$ et al report the usefulness of $3 \mathrm{D}$ ultrasonography for measuring volume of cervical lymph nodes. They found that a cut off volume of $0.7 \mathrm{~cm}^{3} \mathrm{had}$ a $80 \%$ sensitivity and $90 \%$ specificity for differentiating metastatic from reactive lymphadenopathy [5].

Doppler ultrasonography can evaluate the vascular pattern, displacement of vascularity, vascular resistance and pulsatility index. These features have been reported to have a sensitivity of $88 \%$ for the diagnosis of metastatic nodes and $67 \%$ for lymphoma with a specificity of $100 \%[6]$. Metastatic lymph nodes are reported to have higher resistivity index $(>0.8)$ and pulsatility index $(>1.5)$ than reactive lymph nodes [7]. The limiting feature of Doppler and power ultrasound studies is their inability to distinguish between inflammatory and neoplastic nodes reliably on the basis of their flow pattern. Both metastatic and inflammatory nodes have associated vascularisation, which could appear similar on Doppler scan.

The main distinguishing feature of lymph nodes in lymphoma was a homogeneous pattern. In our study on 14 patients with lymphoma the mean $\mathrm{L} / \mathrm{S}$ ratio was $1.5 \pm 0.4$, regular margin was seen in $79 \%(11 / 14)$ and none of them showed internal echoes within the lymph node. This could be attributed to the fleshy nature of these nodes and absence of either calcification or necrosis within them [8].

Ultrasonography is increasingly being recognized as a noninvasive tool for the evaluation of cervical lymph nodes. The sonographic appearance of normal nodes differs from those of abnormal nodes. Sonographic features, which help to identify abnormal nodes, are shape, absent hilus, intranodal necrosis, calcification, matting, peripheral halo and a prominent vascularity. A normal node should be discoid, with a hilus, sharp margins, 
absence of matting, calcification, necrosis or soft tissue edema. The sonographic features of matting are a tendency towards fusion, of calcification is a strong internal echo, of necrosis is an hypoechoic center and of soft tissue edema is a peripheral halo. Distinction between normal and abnormal cervical lymph nodes is fairly straightforward. However distinguishing tubercular from metastatic or lymphomatous lymph nodes is not very precise because of over lapping of many characteristics. The most significant distinguishing feature in our study was strong echoes within the node, which reflects intranodal calcification, caseation and granuloma formation. This was seen in $84 \%$ of tubercular, $11 \%$ of metastatic and none of the lymphomatous or reactive lymph nodes.

A low $\mathrm{L} / \mathrm{S}$ ratio is found in lymph nodes, which have assumed a spherical shape. The lowest ratio of $1.2 \pm 0.3$ was seen in metastatic nodes, $1.5 \pm 0.4$ in lymphomatous, $1.8 \pm 0.6$ in tubercular and in reactive lymph nodes it was $2.2 \pm 0.9$. It is difficult to assign a cut off value separating the 3 categories because of overlap of cases, but this feature can be taken into consideration with other findings while arriving at a diagnosis. Other characteristics like irregular margin, hypoechoic center, fusion tendency and peripheral halo can be used to distinguish normal from abnormal nodes but are not of value in distinguishing between the 3 important causes of cervical lymphadenopathy.

\section{Conclusion}

We conclude that ultrasonographic examination of cervical lymph nodes can yield important information regarding the diagnosis. The sonographic features should be used in conjunction with FNAC findings and may be especially helpful in cytologically indeterminate cases. Ultrasound examination should be done prior to FNAC and ideally an ultrasound guided FNAC sample should be obtained from the most sonographically representative node to reduce the sampling error. A lymph node biopsy can often be avoided by utilizing a combination of FNAC and ultrasonographic examination of the neck nodes.

\section{Author details}

'Department of Surgery, Institute of Medical Sciences, Banaras Hindu University, Varanasi - 221 005, India. ²Department of Pathology, Institute of Medical Sciences, Banaras Hindu University, Varanasi - 221 005, India.

${ }^{3}$ Department of Radiodiagnosis, Institute of Medical Sciences, Banaras Hindu University, Varanasi - 221005 , India.

\section{Authors' contributions}

RK wrote the manuscript and supervised the work. ADS did the data collection and reviewed literature. SK did data analysis and writing of manuscript. MK did the FNAC. RCS did the ultrasonography. All authors read and approved the final manuscript.

\section{Competing interests}

The authors declare that they have no competing interests.
Received: 31 May 2010 Accepted: 28 February 2011

Published: 28 February 2011

\section{References}

1. Haque MA, Talukder SI: Evaluation of fine needle aspiration cytology (FNAC) of lymphnodes in Mymensingh. Mymensingh Med J 2003, 12(11):33-5.

2. Ying $M$, Ahuja $A$, Evans $R$, et al: Cervical lymphadenopathy: sonographic differentiation between tuberculous nodes and nodal metastases from non-head and neck carcinomas. J Clin Ultrasound 1998, 26:383-389.

3. Asai S, Miyachi H, Suzuki K, Shimamura K, Ando Y: Ultrasonographic differentiation between tuberculous lymphadenitis and malignant lymph nodes. J Ultrasound Med 2001, 20:533-538.

4. Steinkamp HJ, Cornehl M, Hosten N, Pegios W, Vogl T, Felic R: Cervical lymphadenopathy: ratio of long to short axis diameter as a predictor of malignancy. Br J Radiol 1995, 68(807):266-70.

5. Kim HC, Han MH, Do KH, Kim KH, Choi HJ, Kim AY, Sung MW, Chang KH: Volume of cervical lymph nodes using $3 \mathrm{D}$ ultrasonography.

Differentiation of metastatic from reactive lymphadenopathy in primary head and neck malignancy. Acta Radiol 2002, 43(6):571-4.

6. Ying $M$, Ahuja A, Brook F: Accuracy of sonographic vascular features in differentiating different causes of cervical lymphadenopathy. Ultrasound Med Biol 2004, 30(4):441-7.

7. Ho SS, Metreweli C, Ahuja AT: Does anybody know how we should measure Doppler parameters in lymph nodes? Clinical Radiology 2001, 56:124-126.

8. Mikami Y, Kamato S, Kawobata K, Nigaari T, Hoki K, Mitani H, Beppu T: Ultrasonographic evaluation of metastatic cervical lymph nodes in head and neck cancers. Nippon Jibiinkoka Gakkai Kaiho 2000, 103(7):812-20.

doi:10.1186/1477-7819-9-29

Cite this article as: Khanna et al.: Usefulness of ultrasonography for the evaluation of cervical lymphadenopathy. World Journal of Surgical

Oncology 2011 9:29.

\section{Submit your next manuscript to BioMed Central and take full advantage of:}

- Convenient online submission

- Thorough peer review

- No space constraints or color figure charges

- Immediate publication on acceptance

- Inclusion in PubMed, CAS, Scopus and Google Scholar

- Research which is freely available for redistribution

Submit your manuscript at www.biomedcentral.com/submit
C Biomed Central 